\title{
Assessment of Nutritional Status, Eating Attitude and Body Satisfaction of University Students
}

\section{Nural Erzurum Alim* and Rahime Evra Karakaya}

Department of Nutrition and Dietetics, Ankara Yildirim Beyazit University, Turkey

*Corresponding Author: Nural Erzurum Alim, Department of Nutrition and

Dietetics, Ankara Yıldırım Beyazıt University, Turkey.
Received: May 13, 2021

Published: June 25, 2021

(C) All rights are reserved by Nural Erzurum

Alim and Rahime Evra Karakaya.

\begin{abstract}
Body perception and nutritional behavior of university students differ due to environmental factors which lead to increased risk of obesity. The aim of this study is to evaluate body perception, eating attitudes and nutritional status of university students'. A questionnaire form including general information and nutritional habits were applied to university students. Body weight and height were measured by a trained researcher. Body perception was evaluated by Body Cathexis Scale and nutritional behavior was assessed by Eating Attitude Test-40. The study was conducted with 343 university students (15.7\% male and $84.3 \%$ female). The prevalence of overweight was $13.1 \%$ and obesity was $2.3 \%$. Higher risk of abnormal eating attitudes were detected in overweight group (21.2\%) than underweight (12.1\%) and obese group (3.0\%) ( $\mathrm{p}>0.05)$. Mean body cathexis scale total score was higher in normal weight group (143.40 \pm 22.99$)$ than overweight, underweight and obese group (141.93 $\pm 23.34,139.86 \pm 21.29,131.50 \pm 21.08$ respectively) ( $p>0.05)$. Eating attitude test and meal frequency weren't significant predictors of body mass index $(B=0.028, p=0.059 ; B=0.478$, $\mathrm{p}=0.083$, respectively). Abnormal nutritional status such as underweight, overweight and obesity could be a potential risk among university students. Risk of abnormal eating attitudes was observed whereas body satisfaction was similar in these groups.
\end{abstract}

Keywords: Body Image; Eating; Obesity; Students

\section{Abbreviations}

BMI: Body Mass Index; WHO: World Health Organization; EAT-40: Eating Attitude Test-40; BC: Body Cathexis; SPSS: The Statistical Package for Social Sciences

\section{Introduction}

Nutrition describes the adequate and balanced intake of nutrients that the body needs for growth, development, maintenance of life and protection of health. Inadequate and unbalanced nutrition in the education process may have negative impacts on physical and mental development. In addition, unhealthy eating habits causes learning difficulties, behavioral disorders and mental retardation [1].
University students become more exposed to external factors for various social, economic or psychological alterations which affect their desire to make free choices by changing dietary habits [2]. During this period, students' eating habits change depending on economic deficiencies, diseases, special situations such as pregnancy, lactation and etc., psychosocial and sociocultural factors, traditions, personal beliefs and value judgments leading to altered energy, and nutrient intake, meal skipping, physical inactivity, fast food addiction, alcohol consumption and tobacco smoking which may result in eating disorders, obesity and other metabolic diseases. All in all, the unhealthy habits acquired in this period passes on later life [3]. Hilger., et al. [3] reported that students eating behavior 
changed due to lack of healthy meal at school and lack of time, being away from hometown, and financial issues. Moreover $18.6 \%$ od male students and $7.4 \%$ female students indicated that they didn't enjoy eating healthy food.

In this education period, as nutritional behavior changes with body structure, aesthetic appearance becomes the most important perception among young people. This concept brings about the idea of being thin and beautiful and yet it may cause eating behavior disorders via unconscious dieting [4]. A research revealed that body satisfaction score was negatively correlated eating attitude score $(r=-0.13, p<0.05)$ in female university students [5].

Unhealthy eating patterns among university students may lead to increased body mass index (BMI). Moreover, eating disorders triggered by body dissatisfaction alters nutritional habits leading to weight gain which was stated in several studies that individuals who are struggling with eating disorders had experienced obesity at any time in their lives [6]. On the other hand, obesity may contribute to eating disorders as weight loss intervention programmes are not applied properly, individuals lean to change their eating patterns in a restricted way such as anorexia nervosa, bulimia nervosa, orthorexia nervosa or binge eating and etc. Finally, eating disorders, body dissatisfaction and obesity interact with each other as a cause-effect relationship may be observed [7]. A study was conducted to reveal the relationship between eating attitudes and body satisfaction with BMI $(r=0.03, p>0.05 ; r=-0.15, p<0.05$ respectively) [5].

All in all, university students may be at high risk for obesity as their body perceptions and nutritional behavior differ due to changing environmental factors. Therefore, determining body perception and eating attitude is of great importance in prevention of unhealthy eating patterns and obesity.

\section{Aim of the Study}

The aim of this study is to evaluate body perception, eating attitudes and nutritional status of university students'.

\section{Materials and Methods \\ Design}

This study was conducted to evaluate body perception, eating attitudes and nutritional status of 343 voluntary university students from Departments of Nutrition and Dietetics, Nursing, Physi- cal Therapy and Rehabilitation, Audiology, Child Development and Medicine at Ankara Yıldırım Beyazıt University from May 2019 to July 2019 in Ankara, Turkey. Data were collected via a questionnaire form consisting of 5 sections. The questionnaire was applied to the participants by face-to-face interview method. The information obtained from participants were kept confidential. The study was approved by the Institutional Review Board and Ethics Committee of Ankara Ylldırım Beyazıt University (Project Year/No: 2019/198) and all the subjects were given written consents in accordance with the Declaration of Helsinki.

\section{General information of participants}

This section includes questions about sociodemographic characteristics (gender, tobacco smoking, alcohol consumption, coexistent disease, family history of obesity and physical activity status) of participants'.

\section{Nutritional habits}

Dieting status, meal frequency, snack frequency were questioned to assess the nutritional habits of students'.

\section{Anthropometric measurements}

Body weight was measured with light clothing and barefooted using Tanita Body Composition Analyzer UM-073. Height was measured via Seca 206 stadiometer in a standing position with head at Frankfort plane. Body weight and height were measured by a trained researcher. The BMI was calculated as 'weight $(\mathrm{kg}) /$ height $\mathrm{x}$ height (m2)' and categorized according to the World Health Organization (WHO) criteria [8].

\section{Eating attitude test-40}

Eating Attitude Test-40 was developed to assess eating behaviors and the symptoms of Anorexia Nervosa by Garner and Garfinkel [9]. EAT- 40 consists of 40 items with a 6 points Likert scale including 'always', 'very often' 'often', 'sometimes', 'rarely' and 'never' options. The grading of items $1,18,19,23,27,39$ is 3 point for 'never', 2 point for 'rarely', 1 point for 'sometimes' and 0 point for the other options. The rest of the items were graded as 3 point for 'always', 2 point for 'very often', 1 point for 'often' and 0 point for other options. Total score is summed up and calculated. The cutoff point the scale is determined as 30 . Total score above 30 points expresses abnormal eating behavior whereas below 30 points indicates low risk. The reliability and validity of the EAT-40 scale was conducted by Savasir and Erol [10] in Turkey. 
Body cathexis scale

Body Cathexis Scale was developed to determine the satisfaction level of individuals' several body parts (arm, ear, hair, height and etc.) and their functions (gastrointestinal system functions, resistance to diseases and etc.) by Secord and Jourard [11]. A 5 points Likert scale (1: I don't like it at all, 2: I don't like it, 3: I am not sure, 4: I like it, 5: I like it a lot) consisting of 40 items is scored and total score is calculated at least 40 up to 200 . The scale doesn't have any cutoff point and higher points indicate higher satisfaction level. The reliability and validity of the $\mathrm{BC}$ scale was conducted by Hovardaoglu [12] in Turkey.

\section{Statistics}

The groups were determined by descriptive statistics. Kolmogorov-Smirnov test was applied to assess the normal distribution. The chi-square test was used for comparison of qualitative data. One way ANOVA test was performed for difference of averages between more than two categories. Pearson correlation coefficient was used to evaluate the correlation between quantitative variables. The correlation between dependent and independent variables was assessed using multiple regression analysis. The level of significance was determined as $\mathrm{p}<0.05$. Data analysis was performed using The Statistical Package for Social Sciences (SPSS) version 21.0.All the materials and methods that are used to complete the study should be mentioned.

\section{Results and Discussion}

The study was conducted with 343 university students $(15.7 \%$ male and $84.3 \%$ female). Participants declared that $18.4 \%$ were current smoker and $19.2 \%$ were alcohol drinkers. The prevalence of coexistent disease of students such as diabetes, asthma, anemia and etc. was $7.6 \%$. Obesity was present in $10.2 \%$ of first degree relatives of students'. Physical activity prevalence was found as $25.9 \%$ among university students (Table 1).

Table 2 reveals that prevalence of students with underweight is $14.3 \%$, normal weight is $70.3 \%$, overweight is $13.1 \%$ and obesity is $2.3 \%$. Among them $6.7 \%$ stated to be on a diet. Students who consumed main meal 3 times/day was found to be $55.1 \%$. Also, snacking between meals for 3 times/day was $11.4 \%$ among participants.

Students of prevalence with abnormal eating attitudes at low risk were higher in normal weight group (71.0\%) than overweight $(12.3 \%)$ and obese group (2.3\%) and yet the difference wasn't

\begin{tabular}{|l|c|c|}
\hline & n & \% \\
\hline Gender & & \\
\hline Male & 54 & 15.7 \\
\hline Female & 289 & 84.3 \\
\hline Smoking status & & \\
\hline Current smoker & 63 & 18.4 \\
\hline Non-smoker & 252 & 73.4 \\
\hline Former smoker & 28 & 8.2 \\
\hline Alcohol consumption & & \\
\hline Drinkers & 66 & 19.2 \\
\hline Non-drinkers & 264 & 77.0 \\
\hline Former drinkers & 13 & 3.8 \\
\hline Coexistent disease & & \\
\hline Yes & 26 & 7.6 \\
\hline No & 317 & 92.4 \\
\hline Family history of obesity & & \\
\hline Yes & 35 & 10.2 \\
\hline No & 308 & 89.8 \\
\hline Physical activity & & \\
\hline Yes & 89 & 25.9 \\
\hline No & 254 & 74.1 \\
\hline
\end{tabular}

Table 1: Sociodemographic characteristics of students.

\begin{tabular}{|l|c|c|}
\hline \multicolumn{1}{|c|}{ Dieting } & n & \% \\
\hline Yes & 23 & 6.7 \\
\hline No & 320 & 93.3 \\
\hline Meal frequency & & \\
\hline Less than 3 times/day & 138 & 40.2 \\
\hline 3 times/day & 189 & 55.1 \\
\hline More than 3 times/day & 16 & 4.7 \\
\hline Snack frequency & & \\
\hline Less than 3 times/day & 295 & 86.0 \\
\hline 3 times/day & 39 & 11.4 \\
\hline More than 3 times/day & 9 & 2.6 \\
\hline BMI & & \\
\hline Underweight & 49 & 14.3 \\
\hline Normal & 241 & 70.3 \\
\hline Overweight & 45 & 13.1 \\
\hline Obese & 8 & 2.3 \\
\hline
\end{tabular}

Table 2: Nutritional habits and nutritional status of participants'. BMI: Body mass index. 
significant ( $\mathrm{p}>0.05$ ). On the other hand, higher risk of abnormal eating attitudes were detected in overweight group $(21.2 \%)$ than underweight (12.1\%) and obese group (3.0\%) while no significant difference was observed ( $\mathrm{p}>0.05)$. Mean body cathexis scale total score was higher in normal weight group (143.40 \pm 22.99$)$ than overweight, underweight and obese group $(141.93 \pm 23.34,139.86$ $\pm 21.29,131.50 \pm 21.08$ respectively). The difference wasn't found significant $(\mathrm{p}>0.05)$ (Table 3$)$.

Correlation analysis indicated that there was a significant positive relationship between BMI with eating attitude test and meal frequency $(r=0.100, p=0.033 ; r=0.091, p=0.046)$. No significant relationship was found between other variables (Table 4).

\begin{tabular}{|c|c|c|c|c|c|c|c|c|c|c|c|}
\hline \multirow[b]{2}{*}{ EAT-40 } & \multicolumn{2}{|c|}{$\begin{array}{l}\text { Underweight } \\
\text { (n:49) }\end{array}$} & \multicolumn{2}{|c|}{$\begin{array}{l}\text { Normal } \\
(n: 241)\end{array}$} & \multicolumn{2}{|c|}{$\begin{array}{c}\text { Overweight } \\
\text { (n:45) }\end{array}$} & \multicolumn{2}{|c|}{$\begin{array}{c}\text { Obese } \\
\text { (n:8) }\end{array}$} & \multicolumn{3}{|c|}{ Total (n:343) } \\
\hline & $\mathrm{n}$ & $\%$ & $\mathrm{n}$ & $\%$ & $\mathrm{n}$ & $\%$ & $\mathrm{n}$ & $\%$ & $\mathrm{p}$ & $\mathrm{n}$ & $\%$ \\
\hline Low risk & 45 & 14.5 & 220 & 71.0 & 38 & 12.2 & 7 & 2.3 & 0.523 & 310 & 90.4 \\
\hline High risk & 4 & 12.2 & 21 & 63.6 & 7 & 21.2 & 1 & 3.0 & & 33 & 9.6 \\
\hline $\mathrm{BC}$ & $\bar{x}$ & $\pm S D$ & $\bar{x}$ & \pm SD & $\bar{x}$ & \pm SD & $\bar{x}$ & \pm SD & 0.404 & $\bar{x}$ & \pm SD \\
\hline Mean Score & 139.86 & 21.29 & 143.40 & 22.99 & 141.93 & 23.34 & 131.50 & 21.08 & & 142.42 & 22.76 \\
\hline
\end{tabular}

Table 3: Eating attitudes and mean body cathexis according to BMI groups.

BMI: Body mass index, EAT-40: Eating Attitude Test-40, BC: Body Cathexis scale, $\mathrm{p}<0.05$.

\begin{tabular}{|l|c|c|c|c|c|c|c|c|c|c|}
\hline & \multicolumn{2}{|c|}{ BMI } & \multicolumn{2}{c|}{ EAT-40 } & \multicolumn{2}{c|}{ BC } & \multicolumn{2}{c|}{ Meal frequency } & \multicolumn{2}{c|}{ Snack frequency } \\
\hline & $\mathbf{r}$ & $\mathbf{p}$ & $\mathbf{r}$ & $\mathbf{p}$ & $\mathbf{r}$ & $\mathbf{p}$ & $\mathbf{r}$ & $\mathbf{p}$ & $\mathbf{r}$ & $\mathbf{p}$ \\
\hline BMI & - & - & - & - & - & - & - & - & - & - \\
\hline EAT-40 & 0.100 & 0.033 & - & - & 0.021 & 0.352 & - & - & - & - \\
\hline BC & -0.043 & 0.211 & & & - & - & - & - & - & - \\
\hline Meal frequency & 0.091 & 0.046 & -0.022 & 0.342 & 0.065 & 0.113 & - & - & - & - \\
\hline Snack frequency & -0.088 & 0.051 & -0.081 & 0.068 & -0.060 & 0.134 & 0.086 & 0.056 & - & - \\
\hline
\end{tabular}

Table 4: Correlation between BMI, eating attitude, body cathexis scale, meal frequency, and snack frequency. BMI: Body mass index, EAT-40: Eating Attitude Test-40, BC: Body Cathexis scale; $p<0.05$.

Multiple linear regression analysis was performed with independent variables such as EAT-40 score and meal frequency which were thought to have an effect on dependent variable BMI. According to analysis, $1 \%$ of the variance in BMI was explained by independent variables $(F=3.229, p=0.041)$. Eating attitude test and meal frequency weren't significant predictors of BMI $(B=0.028, p$ $=0.059 ; \mathrm{B}=0.478, \mathrm{p}=0.083$, respectively) (Table 5).

In the present study, nutritional status, eating attitudes and body cathexis of university students' were analyzed. Eating habits and diet quality are the most decisive lifestyle factors that af- fect students' physical and mental health. The influence of these arouses in the education period or later in adulthood. Therefore, eating habits of university students' have been investigated [13]. During university, teenagers deal with a great pressure about their ideal weight which drives them to diet regularly. Moreno-Gomez., et al. [14] demonstrated that diet quality score was higher in women than men ( $5.04 \pm 1.28$ and $4.86 \pm 1.32$ respectively). Our study results showed that $6.7 \%$ of students were on a diet, which may be the reason that most of the students were on their ideal weight whom might have thought not to need any special diet programme. Furthermore, main meal and snacking frequency are considerable 


\begin{tabular}{|l|c|c|c|c|c|c|c|}
\hline & \multicolumn{2}{|c|}{ Unstandardized Coefficients } & $\begin{array}{c}\text { Standardized } \\
\text { Coefficients }\end{array}$ & \multirow{2}{*}{$\mathbf{t}$} & \multirow{2}{*}{$\mathbf{p}$} & \multicolumn{2}{c|}{$\begin{array}{c}\text { 95\% Confidence } \\
\text { Interval for B }\end{array}$} \\
\cline { 1 - 8 } & B & Standard error & $\beta$ & & & $\begin{array}{c}\text { Lower } \\
\text { Bound }\end{array}$ & $\begin{array}{c}\text { Upper } \\
\text { Bound }\end{array}$ \\
\hline Constant & 20.068 & 0.800 & - & 25.098 & 0.000 & 18.495 & 21.640 \\
\hline EAT-40 & 0.028 & 0.015 & 0.102 & 1.893 & 0.059 & -0.001 & 0.058 \\
\hline Meal frequency & 0.478 & 0.275 & 0.083 & 1.737 & 0.083 & -0.063 & 1.020 \\
\hline
\end{tabular}

Table 5: Multiple regression analysis results for the effect of eating attitude and meal frequency on BMI. $\mathrm{R}=0.137, \mathrm{R}$-square=0.019, Adj-R-square $=0.013, \mathrm{~s}=3.183,(\mathrm{~F}=3.229, \mathrm{p}=0.041)$

BMI: Body mass index, EAT-40: Eating Attitude Test-40, $\mathrm{p}<0.05$.

nutritional habits as they might regulate appetite and prevent overeating. Although longer term evidence suggests that main meal and snack frequency doesn't have effect on insulin and glucose level and energy expenditure, an inverse relationship was revealed between blood lipids and eating frequency [15]. A study including 352 university students revealed that $17.9 \%$ of them had breakfast regularly, and $21.6 \%$ of them snacked three or more times in a day [16]. Current study revealed that $55.1 \%$ of students had 3 times main meal and $11.4 \%$ of them snacked 3 times between meals in a day. Academy of Nutrition and Dietetics revealed that energy requirement should be distributed in meals and snacks during a day including breakfast. However, there is still lack of evidence on impact of eating frequency on weight management [17].

University students may deal with overweight and obesity as their lifestyle habits change during first year to last year of their education. The change of their weight status is mostly related with fast food consumption and sedentary lifestyle [18]. A study conducted in Bangladesh revealed the fact that changing nutritional behaviors in the country in recent years may have effected body weight of university students. They concluded that $14.86 \%$ of students were overweight and $11.86 \%$ were obese [19]. Among Nigerian students high rate of snacking was associated with overweight and obesity. The study revealed that $2.2 \%$ of students were underweight, $57.5 \%$ were normal weight, $31 \%$ were overweight and $9.3 \%$ were obese [20]. A recent study consisted of university students in Turkey showed that $9.6 \%$ of the students were underweight, $69.4 \%$ of them were normal weight and $21.0 \%$ were overweight [21]. Moreover, a cross sectional study including 22 universities from 22 low, middle income and emerging economy countries demonstrated that $22 \%$ of students were overweight and obese. Meal frequency, snack frequency and skipping breakfast were not associated with BMI in male and female students. However trying to eat fiber, avoiding fat and cholesterol and lack of physical inactivity were associated with overweight and obesity in male and female students [22]. In addition, in a study investigating the relationship between meal skipping, snack consuming and obesity among university students, meal skipper students' BMI was higher than those who didn't ( $26 \pm 0$ and $24 \pm 0$, respectively; $\mathrm{p}=0.001$ ). Also, BMI of those who consumed snacks were higher than those who didn't ( $25 \pm 1$ and $23 \pm 0.3$, respectively; $p=0.000$ ) [23]. Taken all into consideration, our study results are similar with other studies as $14.3 \%$ of students were underweight, $70.3 \%$ were normal weight, $13.1 \%$ were overweight and $2.3 \%$ were obese. On the other hand, meal and snack frequency showed different results as BMI was directly correlated with meal frequency $(r=0.091, p=0.046)$ in this study. These results suggest that more evidence based studies about effect of meal and snack frequency on obesity are needed.

The perception and feelings of students' effecting their thoughts about their body and its functions is described as body image. During university education, physical appearance may change due to nutritional habits. The influence of media, appearance comparison, or family connections lead to body dissatisfaction and weight control strategies which result in eating disorders such as bulimia, binge eating, and etc. Individuals generally practice dietary habits as skipping meals, reducing portion size, and vomiting. Thus body dissatisfaction and unhealthy nutrition pattern may result in increased BMI and obesity [24-27]. A study conducted in Turkey 
revealed that $5.9 \%$ of university students were at high risk in terms of abnormal eating attitude and body dissatisfaction was found in 29.8\% of students. A negative relationship was found between body image perception scale score and variables BMI and EAT-40 score [4]. Another study revealed that $8 \%$ of female university students indicated higher risk in terms of EAT-40 score and mean body cathexis scale score was $144.13 \pm 22$.26. There was a relationship between BMI and body satisfaction ( $r=-0.15, p=0.008)$ whereas no relationship was found between BMI and eating attitude $(r=0.03$, $p>0.05$ ) [5]. Among nursing students results of EAT-40 score indicated that $43.9 \%$ of them were at low risk of abnormal eating while $30.0 \%$ of them were at high risk. Thus, mean body cathexis scale score was $147.07 \pm 29.33$. No significant relationship was observed between eating attitude and body cathexis scale $(r=0.08, p=0.14)$ [28]. As body satisfaction and eating attitudes of underweight, overweight and obese individuals are of great importance, a study revealed that $38.2 \%$ of university students had negative body image and $18.3 \%$ of them had abnormal eating attitudes. There was a relationship between eating attitude and body image score in underweight group ( $r=-0.375, \mathrm{p}<0.05)$, whereas no relationship was found in normal and overweight/obese group $(r=-0.77, p>$ $0.05 ; \mathrm{r}=0.001, \mathrm{p}>0.05$, respectively) [29]. Additionally, another study showed that body image score of overweight and obese university students $(146.71 \pm 26.55)$ were lower than underweight $(148.88 \pm 23.86)$ and normal weight $(148.94 \pm 22.48)$ students ( $p>$ $0.05)$. Furthermore, there wasn't found a relationship between BMI and body image scores ( $r=-0.10, p>0.05)$ [25]. Toral., et al. [30] showed that $26.7 \%$ of undergraduate Brazilian university students had severe body dissatisfaction and $10.1 \%$ of them had abnormal eating attitudes. Overweight and obese students were more dissatisfied with their body image $(\mathrm{PR}(95 \% \mathrm{CI})=1.12(0.88-1.43)$ and 1.17 (0.84-1.64), respectively). Most of these results are consistent with our study as $9.6 \%$ of students demonstrated abnormal eating attitudes and body cathexis scale score was $142.2 \pm 22.76$. The study revealed the fact that most of the students didn't display abnormal eating attitude and body satisfaction was high. Furthermore, there wasn't any difference between BMI groups in terms of abnormal eating attitudes and body cathexis. However, underweight and overweight students demonstrated slightly high prevalence of abnormal eating attitude (12.1\% and $21.2 \%$, respectively) which may be considered as potential risk of abnormal eating behavior in these groups. Furthermore, analysis results revealed that BMI was directly correlated with EAT-40 scale and meal frequency although it wasn't significant after further analysis. Previously mentioned studies either showed negative, positive or no relationship between these variables. Our study may be interpreted as BMI increases with abnormal eating attitude and main meal frequency. Nevertheless, further evidence based studies may assist to achieve certain results.

The limitations of this study are that the study consist of a certain university students. Other universities from different cities could be included in order to generalize the results. Also, prevalence of male students was low compared to female students. Furthermore, questionnaire data were collected as self report which may prevent students to be completely honest although confidentiality was ensured. Besides of that, lifestyle factors such as socioeconomic status, family background, social relationships and health behaviors that may have effect BMI, eating behavior and body satisfaction could be questioned. Last but not least, this cross sectional study may prevent the relationship between variables resulting that longitudinal studies provide exact results. Our strengths include that direct measurements of height and weight were taken which prevents bias. Additionally, validated scales were used to assess the eating behavior and body image which may be used to support future studies. Results and discussion must illustrate and interpret the reliable results of the study.

\section{Conclusion}

The results of this study indicate that abnormal nutritional status such as underweight, overweight and obesity could be a potential risk among university students. In the meantime, risk of abnormal eating attitudes is observed whereas body satisfaction was similar in these groups. In order to reduce the health risk in terms of nutritional status, eating attitude and body image and promote healthy lifestyle habits, several health promotion and education programmes should be applied to university students. Further longitudinal and experimental research is necessary to better understand the relationship between nutritional status, eating attitude and body image among this sample.

\section{Acknowledgements}

The authors thank all the students participated in this study.

\section{Conflict of Interest}

The authors declare that they have no conflict of interests. This research received no specific grant from any funding agency in the public, commercial, or not-for-profit sectors. 


\section{Bibliography}

1. O'neil A., et al. "Relationship between diet and mental health in children and adolescents: a systematic review". American Journal of Public Health 104.10 (2014): e31-e42.

2. Antonopoulou M., et al. "Evaluating Mediterranean diet adherence in university student populations: Does this dietary pattern affect students' academic performance and mental health?". The International Journal of Health Planning and Management 35.1 (2020): 5-21.

3. Hilger J., et al. "Eating behaviour of university students in Germany: Dietary intake, barriers to healthy eating and changes in eating behaviour since the time of matriculation". Appetite 109 (2017): 100-107.

4. Akdevelioglu Y. and Gümüs H. "Eating disorders and body image perception among university students". Pakistan Journal of Nutrition 9.12 (2010): 1187-1191.

5. Oruclular Y and Bariskin E. "Autonomous-related self, eating attitude and body satisfaction in young females". Eating and Weight Disorders-Studies on Anorexia, Bulimia and Obesity 20.3 (2015): 337-343.

6. Villarejo C., et al. "Lifetime obesity in patients with eating disorders: Increasing prevalence, clinical and personality correlates". European Eating Disorders Review 20 (2012): 250-254.

7. Da Luz F Q., et al. "Obesity with comorbid eating disorders: Associated health risks and treatment approaches". Nutrients 10.7 (2018): 829.

8. WHO. "Body Mass Index Classification". 3 Feb (2020).

9. Garner D M and Garfinkel P E. "The Eating Attitudes Test: An index of the symptoms of anorexia nervosa". Psychological Medicine 9.2 (1979): 273-279.

10. Savasır I and Erol N. "Yeme Tutum Testi. Anoreksiya nevroza belirtileri indeksi". Psikoloji Dergisi 7 (1989).

11. Secord P F and Jourard S M. "The appraisal of body-cathexis: body-cathexis and the self". Journal of Consulting Psychology 17.5 (1953): 343.
12. Hovardaoğlu S. "Vücut algısı ölçeği". Psikiyatri, Psikoloji, Psikofarmakoloji (3P) Dergisi 1.1 (1993): 26.

13. El Ansari W., et al. "Eating habits and dietary intake: is adherence to dietary guidelines associated with importance of healthy eating among undergraduate university students in Finland?". Central European Journal of Public Health 23.4 (2015): 306-313.

14. Moreno-Gómez C., et al. "Clustering of lifestyle factors in Spanish university students: the relationship between smoking, alcohol consumption, physical activity and diet quality". Public Health Nutrition 15.11 (2012): 2131-2139.

15. Palmer M A., et al. "To Snack or Not to Snack: What should we advise for weight management?". Nutrition and Dietetics 68.1 (2011): 60-64.

16. Pae M. "Dietary habits and perception toward food additives according to the frequency of consumption of convenience food at convenience stores among university students in Cheongju". Korean Journal of Community Nutrition 21.2 (2016): 140-151.

17. Raynor H A and Champagne C M. "Position of the Academy of Nutrition and Dietetics: interventions for the treatment of overweight and obesity in adults". Journal of the Academy of Nutrition and Dietetics 116.1 (2016): 129-147.

18. Popkin B M., et al. "Global nutrition transition and the pandemic of obesity in developing countries". Nutrition Review 70 (2012): 3-21.

19. Zamsad M., et al. "Prevalence of overweight, obesity and abdominal obesity in Bangladeshi university students: A crosssectional study". Diabetes and Metabolic Syndrome: Clinical Research and Reviews 13.1 (2019): 480-483.

20. Kayode 0O. and Alabi QK. "Food consumption patterns, physical activity and overweight and obesity among undergraduates of a private university in Nigeria". Clinical Nutrition EXperimental 31 (2020): 28-34.

21. Haney MÖ and Öztürk D. "Body Weight and Its Association With Weight Perception, Eating Problems and Physical Activity in University Students". Acıbadem Üniversitesi Sağlık Bilimleri Dergisi 10.2 (2019): 169-175. 
22. Peltzer K., et al. "Prevalence of overweight/obesity and its associated factors among university students from 22 countries". International Journal of Environmental Research and Public Health 11.7 (2014): 7425-7441.

23. Sönmez MO and Nazik F. "Changing Nutrition Habits: Snack Consumption, Meal Skipping And Anthropometric Parameters Of University Students In Turkey". Southeast Asian Journal of Tropical Medicine and Public Health 50.1 (2019): 180-190.

24. Gavin A R., et al. "The association between obesity, depression, and educational attainment in women: the mediating role of body image dissatisfaction". Journal of Psychosomatic Research 69.6 (2010): 573-581.

25. Şanlier N., et al. "Body image, food addiction, depression, and body mass index in university students". Ecology of Food and Nutrition 55.6 (2016): 491-507.

26. Rosewall J K., et al. "An examination of risk factors that moderate the body dissatisfaction-eating pathology relationship among New Zealand adolescent girls". Journal of Eating Disorders 6.1 (2018): 1-10.

27. Gonzalez A., et al. "Eating disorders in adolescents". Australian Family Physician 36.8 (2007): 614-619.

28. Celik S., et al. "Eating attitudes and related factors in Turkish nursing students". Nursing and Midwifery Studies 4.2 (2015): E25479.

29. Tayfur S N and Evrensel A. "Investigation of the relationships between eating attitudes, body image and depression among Turkish university students". Rivista di Psichiatria 55.2 (2020): 90-97.

30. Toral N., et al. "Eating disorders and body image satisfaction among Brazilian undergraduate nutrition students and dietitians". Archivos Latinoamericanos De Nutricion 66.2 (2016): 129-134.

Volume 5 Issue 7 July 2021

(C) All rights are reserved by Nural Erzurum Alim and Rahime Evra Karakaya. 